\title{
Intraoperative acidosis and hypercapnia during thoracoscopic repair of congenital diaphragmatic hernia and esophageal atresia/tracheoesophageal fistula
}

Running head: Acidosis at neonatal thoracoscopy

\section{Research report}

Augusto Zani ${ }^{1}$, Ruben Lamas-Pinheiro ${ }^{1}$, Irene Paraboschi ${ }^{1}$, Sebastian K King ${ }^{1}$, Justyna Wolinska ${ }^{1}$, Elke Zani-Ruttenstock ${ }^{1}$, Simon Eaton ${ }^{2}$, Agostino Pierro ${ }^{1}$

1. Division of General and Thoracic Surgery, The Hospital for Sick Children, Toronto, Ontario, Canada;

2. UCL Institute of Child Health, London, United Kingdom

\section{Corresponding author:}

Dr. A. Zani

Division of General and Thoracic Surgery

The Hospital for Sick Children

1524C-555 University Ave

Toronto, ON M5G 1X8, Canada

augusto.zani@sickkids.ca

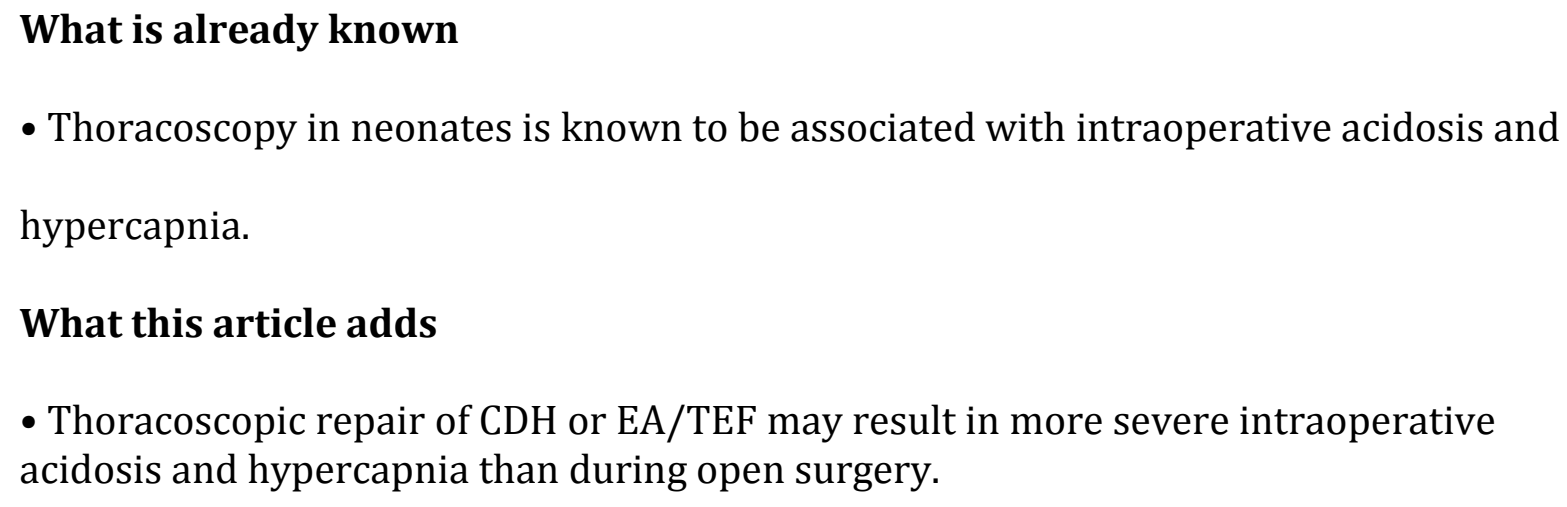

- Thoracoscopy in neonates is known to be associated with intraoperative acidosis and hypercapnia.

\section{What this article adds}

- Thoracoscopic repair of CDH or EA/TEF may result in more severe intraoperative acidosis and hypercapnia than during open surgery. 


\begin{abstract}
Background: Intraoperative hypercapnia and acidosis have been associated with thoracoscopic repair of both congenital diaphragmatic hernia (CDH) and esophageal atresia/tracheoesophageal fistula (EA/TEF).
\end{abstract}

Aim: The aim of the present study was to investigate whether thoracoscopic repair of $\mathrm{CDH}$ or EA/TEF was associated with acidosis and hypercapnia in a large group of neonates, and to analyze the effects of acidosis and hypercapnia on early postoperative outcomes.

Methods. We reviewed the charts of neonates who underwent open or thoracoscopic CDH or EA/TEF repair (2004-2014). Patients with available intraoperative arterial gas values were included. Data $\left(\mathrm{PaCO}_{2}: \mathrm{mmHg}\right)$ were compared using paired/unpaired tests and are reported as difference [95\% confidence interval].

Results. $\underline{C D H}$ : 187 neonates underwent open $(n=153)$ or thoracoscopic $(n=34)$ repair. Intraoperative arterial gas values were recorded in 96 open and in 23 thoracoscopic operations. Both groups had similar preoperative $\mathrm{pH}$ and $\mathrm{PaCO}_{2}$, and developed intraoperative acidosis (open $-0.08[-0.11,-0.05] \mathrm{p}<0.001$, thoracoscopic $-0.14[-0.24$, $0.04] \mathrm{p}=0.01$ ) and hypercapnia (open: $7.8[3.2,12.4], \mathrm{p}=0.002$; thoracoscopic: $20.2[-2.5$, $43, \mathrm{p}=0.07)$. Intraoperatively, neonates undergoing thoracoscopic repair developed lower $\mathrm{pH}$ than those having open surgery $(-0.06[-0.01,-0.10] \mathrm{p}=0.018)$, but maintained similar levels of $\mathrm{PaCO}_{2}(-4.0[-9.0,4.4] \mathrm{p}=0.39) . \underline{E A}$ /TEF: 205 neonates underwent open $(n=180)$ or thoracoscopic $(n=25) E A / T E F$ repair. Intraoperative arterial gas values were recorded in 62 open and in 14 thoracoscopic operations. Both groups had similar preoperative $\mathrm{pH}$ and $\mathrm{PaCO}_{2}$, and developed intraoperative acidosis (open: -0.09 [-0.14, $0.04], \mathrm{p}<0.001$; thoracoscopic: 0.21 [-0.28, -0.14$], \mathrm{p}<0.001$ ) and hypercapnia (open: 9.2 $[2.6,15.7] \mathrm{p}=0.008$; thoracoscopic: 15.2 [1.6, 28.7], $\mathrm{p}=0.03)$. Intraoperatively, neonates undergoing thoracoscopic repair developed lower $\mathrm{pH}$ than those having open surgery (difference 0.08 [0.01, 0.15], $\mathrm{p}=0.02$ ) but maintained similar levels of $\mathrm{PaCO}_{2}$ (difference $-1[-9,3], \mathrm{p}=0.35)$.

Conclusions. Neonates undergoing operative repair of CDH or EA/TEF develop intraoperative acidosis and hypercapnia, regardless of the approach used. However, this phenomenon is more severe during thoracoscopic repair. Novel modalities to reduce intraoperative gas derangements, particularly during thoracoscopic repair, need to be established.

Keywords: acidemia; hypercapnia, hypercarbia, neonate, thoracoscopy, minimally invasive surgery 


\section{Introduction}

Since the first reports on the use of thoracoscopy for congenital anomalies in infants (1-3), this surgical approach has been shown to be effective, safe, and to result in better cosmetic outcome in comparison to open surgery $(\mathbf{4 , 5})$. However, intra-operative acidosis and hypercapnia during thoracoscopy have been reported in some retrospective studies in the pediatric age group (611) and have been confirmed by a pilot randomized controlled trial in neonates undergoing thoracoscopic repair of congenital diaphragmatic hernia $(\mathrm{CDH})$ or esophageal atresia/tracheaesophageal fistula (EA/TEF) (12). Carbon dioxide $\left(\mathrm{CO}_{2}\right)$ is the gas most commonly used to insufflate the body cavities during minimally invasive surgery and may be absorbed, leading to increased arterial $\mathrm{CO}_{2}$ and increased $\mathrm{CO}_{2}$ elimination from the lungs (13). Intra-operative acidosis and hypercapnia during thoracoscopy seem to be associated with an excess of $\mathrm{CO}_{2}$ absorption from thoracic insufflation that, in neonates, is more pronounced than that reported from peritoneal insufflation during pediatric laparoscopy $(\mathbf{1 2}, \mathbf{1 4})$. Despite previous reports, it is still a matter of debate whether severe intraoperative acidosis in neonates undergoing thoracoscopic surgery influences adversely their postoperative outcomes.

The aim of the present study was to investigate whether thoracoscopic repair of CDH or EA/TEF was associated with acidosis and hypercapnia in a large group of neonates, and to analyze the effects of acidosis and hypercapnia on early postoperative outcomes.

\section{Patients and Methods}

We performed a retrospective review of the medical charts of all neonates who underwent open or thoracoscopic repair for posterolateral CDH or EA/TEF between August 2004 and October 2014 at The Hospital for Sick Children, Toronto, Canada. Open repair was via laparotomy for 
$\mathrm{CDH}$ patients and via thoracotomy for EA/TEF patients. Only patients with available intraoperative arterial gas values were included in the present study.

Data included patient demographics, preoperative and intraoperative arterial gas values (nadir $\mathrm{pH}$, nadir $\mathrm{PaO}_{2}$, and zenith $\mathrm{PaCO}_{2}$ ), effect of intraoperative $\mathrm{pH}$ on conversion to open surgery, length of postoperative ventilation, and postoperative complications (hernia recurrence, esophageal stricture). Patients who were converted to open surgery (laparotomy for $\mathrm{CDH}$, thoracotomy for EA/TEF) were considered in the thoracoscopic group for the analysis.

\section{Statistics}

Data were tested for normality distribution using the Kolmogorov-Smirnov test and were compared using parametric (t-test) or non-parametric tests (Mann-Whitney), accordingly; dichotomous data were compared using Fisher's exact test. Intraoperative acidosis was correlated with postoperative ventilation duration using linear regression analysis. Data are reported as mean $\pm \mathrm{SD}$ or median (range). Differences in mean and median are also reported with $95 \%$ confidence intervals (CI), dichotomous data report odds ratios and their $95 \%$ CIs.

\section{Results}

During the study period, 392 neonates underwent surgery for CDH $(n=187)$ or EA/TEF $(n=205)$.

\section{Congenital Diaphragmatic Hernia}

Of the 187 neonates who underwent $\mathrm{CDH}$ repair, 153 had open surgery and 34 thoracoscopic repair. Intraoperative arterial gas values were recorded in 96 (63\%) open and in $23(68 \%)$ thoracoscopic operations. There were no differences in gender (OR 1.5 
$[0.6,3.7] \mathrm{p}=0.5)$, birth weight (difference $-213[-540,115] \mathrm{p}=0.2$ ), gestational age (difference $-0.6[-2.0,0.9] \mathrm{p}=0.4$ ), or side of the defect (OR $1.1[0.3,4.1] \mathrm{p}=1$ ) between those undergoing open and thoracoscopic repair [Table 1]. Neonates who underwent thoracoscopic repair were younger than the ones who had an open repair (difference - 2 $[-3,0], p<0.004)$ [Table 1]. The length of thoracoscopic repair $(163[71,282] \mathrm{min})$ was longer than that of open surgery $(115[46,252]$ min, (difference in medians -48 [-67, 22], $\mathrm{p}=0.0003)$.

There were no differences in preoperative arterial $\mathrm{pH}, \mathrm{PaCO}_{2}$ or $\mathrm{PaO}_{2}$ values between neonates who underwent open or thoracoscopic CDH repair (Table 2). During surgery, the arterial $\mathrm{pH}$ values of open and thoracoscopic groups were lower than the preoperative values, whereas the arterial $\mathrm{PaCO}_{2}$ values had the opposite trend (Figure 1A-D). In addition, the intraoperative nadir arterial $\mathrm{pH}$ values of neonates undergoing $\mathrm{CDH}$ thoracoscopic repair were significantly lower than those of neonates who underwent open surgery (Figure 1E). However, the intraoperative zenith arterial $\mathrm{PaCO}_{2}$ values were not different between those undergoing open and thoracoscopic CDH repair (Figure 1F). Similarly, intraoperative nadir $\mathrm{PaO}_{2}$ values were similar between infants undergoing open surgery and those undergoing thoracoscopy (Table 2).

Thoracoscopy was converted to open surgery in 8/34 (24\%) patients, but only in one neonate was this due to severe intraoperative acidosis. Median postoperative ventilation was 4 days (1-78) after open surgery and 5 days (1-40) after thoracoscopic repair (difference $-1[-3,0], \mathrm{p}=0.14$ ). There was a weak correlation between intraoperative acidosis and postoperative ventilation duration $\left(r^{2}=0.06[0.00,0.18, p=0.01)\right.$. 
At a median follow-up of 3.6 years, there were $6 / 153$ patients $(4 \%)$ in the open surgery group and $7 / 34(21 \%)$ in the thoracoscopic group that developed a diaphragmatic hernia recurrence; this difference was significant (odds ratio $0.15,95 \%$ CI $0.05,0.5 \mathrm{p}=0.0028$ ). The nadir intraoperative $\mathrm{pH}$ at the time of the initial surgery of patients who then developed a hernial recurrence were not different to that who did not recur (difference $0.02[-0.12,0.16], p=0.7$ ).

\section{Esophageal atresia/tracheoesophageal fistula}

During the study period, 205 neonates underwent open $(n=180)$ or thoracoscopic $(n=25)$ EA/TEF repair. Intraoperative arterial gas values were recorded in 62 (34\%) open and in $14(56 \%)$ thoracoscopic operations. Although there was a trend towards those operated thoracoscopically having a higher birthweight and later gestational age, these differences were not significant (difference $-438[-1038,1626], \mathrm{p}=0.2$ and difference $-2.6[-5.3,0.1]$, $\mathrm{p}=0.06$ respectively; Table $\mathbf{1}$ ). The two groups had similar ages at repair (difference 0 [1, 1] $\mathrm{p}=0.8$; Table 1). All neonates in both groups had type C EA/TEF according to the Gross classification. Overall, the length of thoracoscopic repair [244 $\pm 16 \mathrm{~min}$; ] was longer than that of open surgery [189 $\pm 8 \mathrm{~min}$; difference in means $-55(-94$ to -17$) \mathrm{p}=0.006)$.

There were no differences in preoperative arterial $\mathrm{pH}, \mathrm{PaCO}_{2}$ or $\mathrm{PaO}_{2}$ values between neonates who underwent open or thoracoscopic EA/TEF repair (Table 2). The intraoperative arterial $\mathrm{pH}$ values of open and thoracoscopic groups were lower than the preoperative values, whereas the arterial $\mathrm{PaCO}_{2}$ values had the opposite trend (Figure

2A-D). The neonates who underwent thoracoscopic repair had significantly lower nadir intraoperative $\mathrm{pH}$ values than those who underwent open surgery (Figure 2E), whereas there were no differences in intraoperative zenith arterial $\mathrm{PaCO}_{2}$ values (Figure 2F). 
There were no differences in intraoperative lowest $\mathrm{PaO}_{2}$ values between neonates undergoing open surgery and those undergoing thoracoscopy (Table 2).

Five (20\%) patients required a conversion from thoracoscopic to open surgery; however, these were not due to ventilatory concerns. Median postoperative ventilation was 2 days (0-21) after open surgery and 3 days (1-8) after thoracoscopy (difference in medians -1, $[-2,2], p=1.0)$. There was a weak correlation between intraoperative acidosis and postoperative ventilation duration $\left(\mathrm{r}^{2}=0.07\right.$ [95\% CI 0.00, 0.24], $\left.\mathrm{p}=0.04\right)$.

At a median follow-up of 46 months, 10/180 (6\%) patients in the open surgery group and 6/25 (24\%) in the thoracoscopic group had developed an esophageal stricture that required balloon dilatation; this difference was significant (odds ratio $0.19[0.06,0.57] \mathrm{p}=0.006$ ). The levels of intraoperative acidosis at the time of the first surgery were not different between those patients who developed a stricture and those who did not (difference $-0.02[-0.22,0.18] \mathrm{p}=0.8$ ).

\section{Discussion}

The current study shows that, whilst open repair of CDH or EA/TEF is associated with an intraoperative alteration of blood gases, neonates undergoing thoracoscopic repair develop a greater degree of intraoperative acidosis. Overall, the results of the current study support previous reports in the literature addressing the occurrence of intraoperative acidosis in the same population of neonates (Table 3). However, some of these previous studies included only patients repaired thoracoscopically, some were not comparative, and most comprised a small number of patients (Table 3).

The hypercapnia during thoracoscopy was first reported in 2009 by Bliss et al. (6). The authors described it as a common phenomenon during thoracoscopic CDH repair, but 
concluded that in their series it did not result in clinically evident deterioration. McHoney et al. (8) confirmed the phenomenon, and also reported that end-tidal $\mathrm{CO}_{2}$ levels were higher in infants undergoing thoracoscopic repair of $\mathrm{CDH}$ than in those undergoing open surgery. This study recommended a close monitoring of intraoperative arterial blood gases and advocated for a randomized trial to assess the effect of thoracoscopy on ventilation and CDH recurrences (8). Almost concomitantly, Fishman et al. reported that patients with $\mathrm{CDH}$ repaired thoracoscopically developed similar intraoperative acidosis levels to those repaired with open surgery (9). However, careful scrutiny of the pH values reported in that series reveals the intraoperative degree of acidosis to reach levels as low as 6.61 (9). In addition, arterial blood gases are not taken at specified times during the procedures, so that there may be more blood gases values measured during thoracoscopic procedures, both due to the longer operative times and the perceived higher risk of acidosis, resulting in a bias in comparison of open and thoracoscopic blood gas values.

So far there has been only a single pilot randomized controlled trial that compared open versus thoracoscopic surgery addressing the issue of intraoperative acidosis (12). The findings of this trial did not support the use of thoracoscopy for $\mathrm{CDH}$ repair with $\mathrm{CO}_{2}$ insufflation and conventional ventilation, calling into question the safety of this practice (12). On the other hand, as there were no significant differences in $\mathrm{PaCO}_{2}$ or $\mathrm{pH}$ between neonates undergoing open and thoracoscopic repair of EA/TEF, the authors concluded that the effect of thoracoscopy on blood gases in this population required further evaluation, as only $10 \mathrm{EA} / \mathrm{TEF}$ had been compared in the pilot study (12).

Most of the studies published on this topic have attempted to answer the question 
whether the presence of intraoperative acidosis has had a negative clinical impact upon patients. To date, none of the reported studies has ever documented a clinical compromise of the neonates during the intra- or post-operative period. In our current study, we have shown that only one infant undergoing $\mathrm{CDH}$ repair developed such a profound acidosis that conversion to open surgery was required. The other 12 converted cases were the result of other reasons. This is similar to the experience reported in the randomized trial, where there were no cases of thoracoscopy for CDH or EA/TEF converted to open surgery due to ventilatory concerns (12).

In the current study we also determined that neither the thoracoscopic approach, nor the levels of intraoperative acidosis, influenced the duration of postoperative mechanical ventilation. This is similar to that reported in the pilot randomized trial, where there was no difference in days of postoperative ventilation and intensive care unit stay between the open and the thoracoscopic group (12).

The current study also looked at whether severe levels of acidosis during thoracoscopy in neonates could result in higher postoperative complication rates, namely hernial recurrence for $\mathrm{CDH}$ patients and esophageal stricture for EA/TEF. At follow-up, there appears to be a significantly higher rate of hernia recurrences in the CDH group and esophageal stricture of the anastomosis in the EA/TEF group. The high recurrence rate in thoracoscopic $\mathrm{CDH}$ repair has been previously reported in a meta-analysis (19), but an association with intra-operative acidosis is unlikely. Likewise, thoracoscopic repair has been reported as one of the factors associated with increased risk of clinically significant stricture formation after EA/TEF repair (20). 
The issue of whether severe intraoperative acidosis has an impact on the infant developing brain is still a matter of debate. Bishay et al. (15) measured the regional cerebral oxygen saturation using near-infrared spectroscopy in six infants undergoing thoracoscopic $\mathrm{CDH}$ or EA/TEF repair and reported that intraoperative acidosis was associated with a decrease in cerebral hemoglobin oxygen saturation. More recently, Tytgat et al., studying the impact of thoracoscopy for EA/TEF at a low $\mathrm{CO}_{2}$ insufflation pressure ( $5 \mathrm{mmHg}$ ), confirmed a reversible decrease in oxygen saturation and $\mathrm{pH}$, and an increase in $\mathrm{PaCO}_{2}$ (16). The authors concluded that the regional cerebral oxygen saturation remained stable and within normal limits during and after the $\mathrm{CO}_{2}$ pneumothorax, suggesting no hampering of cerebral oxygenation by thoracoscopy (16).

It remains unknown whether acidosis and hypercapnia in the presence of normoxia are detrimental for infantile neurodevelopment. In the preliminary study by Bishay et al., as well as in the randomized controlled trial, arterial oxygenation was well maintained throughout $(\mathbf{1 2}, \mathbf{1 5})$. Similarly, in our current study, patients who underwent thoracoscopy did not have changes in arterial oxygenation. It could be that maintaining a good cerebral oxygen saturation prevents cerebral damage, regardless of the changes in the other gas parameters.

As the acidosis phenomenon is now recognized, strategies to prevent it have been proposed. Acidosis could arise either due to respiratory compromise during thoracoscopic procedures due to, for example, lung collapse to allow a working space, or direct absorption of insufflated $\mathrm{CO}_{2}$ from the thorax. On the other hand, the lower intraoperative $\mathrm{pH}$ levels found in neonates undergoing thoracoscopy in comparison to those having open surgery could be due to a component of metabolic acidosis. An acid- 
base imbalance, mostly of a metabolic type, has been reported in patients undergoing laparoscopy [21], but to the best of our knowledge it has not been reported in neonates undergoing thoracoscopy. Data from Bishay et al. suggest that direct absorption of insufflated $\mathrm{CO}_{2}$ from the thorax is an important factor, as during thoracoscopic procedures up to $50 \%$ of expired $\mathrm{CO}_{2}$ originated from the insufflated gas (12). Mortellaro et al. (10) recommended the use of high-frequency oscillating ventilation to facilitate $\mathrm{CO}_{2}$ elimination and to prevent acidosis in neonates undergoing thoracoscopic $\mathrm{CDH}$ or EA/TEF repair. Studies focused upon the optimal insufflation gas for laparoscopy have proposed the use of nitrous oxide, helium, argon, or air for insufflation. However, a systematic review of the literature found no randomized controlled trials comparing $\mathrm{CO}_{2}$ pneumoperitoneum to any other gas pneumoperitoneum and could not demonstrate any advantage of alternative gases over $\mathrm{CO}_{2}(\mathbf{1 7})$. Other gases may introduce additional risks of potentially greater clinical significance, such as embolism. The best strategy to minimize intraoperative hypercapnia and acidosis would be to use $\mathrm{CO}_{2}$ insufflation at very low pressures, possibly insufflating only at the beginning of the operation, especially in $\mathrm{CDH}$.

We acknowledge the limitations of the current study, mainly due to its retrospective nature. In our series, not all patients had arterial gas values checked and recorded intraoperatively and the ones available were not taken at set time points. Nonetheless, if gas values were available for all patients we believe that the degree of intraoperative acidosis and hypercapnia could have been even greater. Moreover, in this study we have compared patients allocated to open surgery or thoracoscopy on clinical grounds, which implies a selection bias whereby neonates allocated to thoracoscopic surgery typically have a more robust preoperative physiology. Yet, we have recorded a greater change in 
$\mathrm{pH}$ and $\mathrm{PaO} 2$ values in this population of neonates.

In conclusion, the present study shows that neonates undergoing surgical repair of CDH or EA/TEF develop intraoperative acidosis and hypercapnia regardless of the approach used. However, this phenomenon is more severe during thoracoscopic repair. Although the finding of acidosis is concerning, we found no association of intraoperative acidosis with any other postoperative outcome of immediate interest. The effects of acidosis and hypercapnia on cerebral development are unknown, but maintaining adequate arterial oxygenation could be key to prevent damage. It would be important for future prospective studies to document intra-operative acidosis systematically, and to establish whether there are any long-term effects on neurological or other relevant outcomes. This would be difficult to do except as a multi-centre randomized controlled trial, as there are likely to be several confounders influencing neurodevelopmental outcomes in these groups of infants.

This study highlights that even in a large volume center a noticeable proportion of neonates undergoing thoracoscopic surgery did not routinely have arterial blood gas levels checked intraoperatively. The findings of the current study have made surgeons and anesthetists aware of the occurrence of intraoperative acidosis and hypercapnia, prompting the surgeons to use low insufflation settings and the anesthetists to meticulously check neonatal physiology intraoperatively.

We advocate for a large multicenter randomized controlled trial of open versus thoracoscopic $\mathrm{CDH}$ or EA/TEF repair at low $\mathrm{CO}_{2}$ insufflation pressures. 


\section{Ethics}

The study was registered with the institutional Ethics committee (REB1000046560 and REB1000046653),

\section{Funding}

This study was supported by the endowment of the Robert M Filler Chair of Surgery, The Hospital for Sick Children.

\section{Disclosures}

The authors have nothing to disclose. 


\section{References}

1. Bax KM, van Der Zee DC. Feasibility of thoracoscopic repair of esophageal atresia with distal fistula. J Pediatr Surg 2002; 37: 192-196.

2. Rothenberg SS. Thoracoscopic repair of tracheoesophageal fistula in newborns. $J$ Pediatr Surg 2002; 37: 869-872.

3. Liem NT. Thoracoscopic surgery for congenital diaphragmatic hernia: a report of nine cases. Asian J Surg 2003; 26: 210-212.

4. Lacher M, Kuebler JF, Dingemann J, et al. Minimal invasive surgery in the newborn: current status and evidence. Semin Pediatr Surg 2014; 23: 249-256.

5. Laje P, Pearson EG, Simpao AF, et al. The first 100 infant thoracoscopic lobectomies: Observations through the learning curve and comparison to open lobectomy. J Pediatr Surg 2015; 50: 1811-1816.

6. Bliss D, Matar M, Krishnaswami S. Should intraoperative hypercapnea or hypercarbia raise concern in neonates undergoing thoracoscopic repair of diaphragmatic hernia of Bochdalek? J Laparoendosc Adv Surg Tech A 2009; 19: S55-58.

7. Gourlay DM, Cassidy LD, Sato TT, et al. Beyond feasibility: a comparison of newborns undergoing thoracoscopic and open repair of congenital diaphragmatic hernias. J Pediatr Surg 2009; 44: 1702-1707.

8. McHoney M, Giacomello L, Nah SA, et al. Thoracoscopic repair of congenital diaphragmatic hernia: intraoperative ventilation and recurrence. J Pediatr Surg 2010; 45: 355-359.

9. Fishman JR, Blackburn SC, Jones NJ, et al. Does thoracoscopic congenital diaphragmatic hernia repair cause a significant intraoperative acidosis when compared to an open abdominal approach? J Pediatr Surg 2011; 46: 458-461. 
10. Mortellaro VE, Fike FB, Adibe 00, et al. The use of high-frequency oscillating ventilation to facilitate stability during neonatal thoracoscopic operations. $J$ Laparoendosc Adv Surg Tech A 2011; 21: 877-879.

11. Okazaki T, Okawada M, Koga $\mathrm{H}$, et al. Safety of surgery for neonatal congenital diaphragmatic hernia as reflected by arterial blood gas monitoring: thoracoscopic versus open repair. Pediatr Surg Int 2015; 31: 899-904.

12. Bishay M, Giacomello L, Retrosi G, et al. Hypercapnia and acidosis during open and thoracoscopic repair of congenital diaphragmatic hernia and esophageal atresia: results of a pilot randomized controlled trial. Ann Surg 2013; 258: 895-900.

13. Eaton S, McHoney M, Giacomello L, et al. Carbon dioxide absorption and elimination in breath during minimally invasive surgery. J Breath Res 2009; 3: 047005.

14. Pacilli M, Pierro A, Kingsley C, et al. Absorption of carbon dioxide during laparoscopy in children measured using a novel mass spectrometric technique. $\mathrm{Br}$ J Anaesth 2006; 97: 215-219.

15. Bishay M, Giacomello L, Retrosi G, et al. Decreased cerebral oxygen saturation during thoracoscopic repair of congenital diaphragmatic hernia and esophageal atresia in infants. J Pediatr Surg 2011; 46: 47-51.

16. Tytgat SH, van Herwaarden MY, Stolwijk LJ, et al. Neonatal brain oxygenation during thoracoscopic correction of esophageal atresia. Surg Endosc 2015 Oct 21.

17. Cheng Y, Lu J, Xiong X, et al. Gases for establishing pneumoperitoneum during laparoscopic abdominal surgery. Cochrane Database Syst Rev 2013; 1: CD009569.

18. Ma L, Liu YZ, Ma YQ, et al. Comparison of neonatal tolerance to thoracoscopic and open repair of esophageal atresia with tracheoesophageal fistula. Chin Med J(Engl) 2012; 125: 3492-3495. 
19. Lansdale N, Alam S, Losty PD, et al. Neonatal endosurgical congenital diaphragmatic hernia repair: a systematic review and meta-analysis. Ann Surg 2010; 252: 20-26.

20. Nice T, Tuanama Diaz B, Shroyer M, et al. Risk Factors for Stricture Formation After Esophageal Atresia Repair. J Laparoendosc Adv Surg Tech A 2016; 26: 393398.

21. Gándara V, de Vega DS, Escriú N, Zorrilla IG. Acid-base balance alterations in laparoscopic cholecystectomy. Surg Endosc. 1997 Jul;11(7):707-10. 
Table 1. Demographics of neonates who underwent open or thoracoscopic CDH or EA/TEF repair.

\begin{tabular}{|c|c|c|c|c|c|}
\hline & Open & Thoracoscopic & $\begin{array}{l}\text { Difference } \\
(95 \% \mathrm{CI}),\end{array}$ & $\begin{array}{l}\text { Odds ratio } \\
(95 \% \mathrm{CI})\end{array}$ & p-value \\
\hline CDH (n) & 96 & 23 & & & \\
\hline Gender (M:F) & $63: 33$ & $13: 10$ & & $\begin{array}{c}1.5 \\
(0.6,3.7)\end{array}$ & 0.5 \\
\hline $\begin{array}{l}\text { Birth weight } \\
\text { (grams) }\end{array}$ & $3115 \pm 597$ & $3327 \pm 565$ & $\begin{array}{c}-213 \\
(-540,115)\end{array}$ & & 0.2 \\
\hline $\begin{array}{l}\text { Gestational age } \\
\text { (weeks) }\end{array}$ & $38.2 \pm 2.6$ & $38.8 \pm 1.6$ & $\begin{array}{c}-0.6 \\
(-2.0,0.9)\end{array}$ & & 0.4 \\
\hline Side of defect (left) & $84(88 \%)$ & $20(87 \%)$ & & $\begin{array}{c}1.1 \\
(0.3,4.1)\end{array}$ & 1 \\
\hline Age at repair (days) & $4(3-8)$ & $2(2-4)$ & $\begin{array}{c}-2 \\
(-3,0)\end{array}$ & & 0.004 \\
\hline EA/TEF (n) & 62 & 14 & & & \\
\hline Gender (M:F) & $37: 25$ & $6: 8$ & & $\begin{array}{c}2.0 \\
(0.6,6.4)\end{array}$ & 0.4 \\
\hline $\begin{array}{l}\text { Birth weight } \\
\text { (grams) }\end{array}$ & $2623 \pm 766$ & $3060 \pm 608$ & $\begin{array}{c}-438 \\
(-1038 \\
1626) \\
\end{array}$ & & 0.2 \\
\hline $\begin{array}{l}\text { Gestational age } \\
\text { (weeks) }\end{array}$ & $37 \pm 3.5$ & $39 \pm 1.5$ & $\begin{array}{c}-2.6 \\
(-5.3,0.1)\end{array}$ & & 0.06 \\
\hline Type of atresia & $\mathrm{C}=100 \%$ & $\mathrm{C}=100 \%$ & & & 1 \\
\hline Age at repair (days) & $2(1-4)$ & $2(1-3)$ & $\begin{array}{c}0 \\
(-1,1)\end{array}$ & & 0.8 \\
\hline
\end{tabular}

Mean \pm SD or median (IQ range); $\mathrm{CI}=$ confidence interval 
Table 2. Preoperative and intraoperative arterial $\mathrm{pH}$ and $\mathrm{PaCO}_{2}$ for neonates who underwent open or thoracoscopic CDH or EA/TEF repair.

\begin{tabular}{|c|c|c|c|c|}
\hline & Open & Thoracoscopic & $\begin{array}{l}\text { Difference } \\
(95 \% \mathrm{CI})\end{array}$ & p-value \\
\hline CDH (n) & 96 & 23 & & \\
\hline Preoperative $p H$ & $7.35 \pm 0.06$ & $7.38 \pm 0.05$ & $\begin{array}{c}-0.03 \\
(-0.07,0.01)\end{array}$ & 0.19 \\
\hline $\begin{array}{l}\text { Preoperative } \\
\mathrm{PaCO}_{2} \\
(\mathrm{mmHg})\end{array}$ & $43(34-79)$ & $41(35-52)$ & $\begin{array}{c}2 \\
(-2,8)\end{array}$ & 0.30 \\
\hline $\begin{array}{l}\text { Preoperative } \mathrm{PaO}_{2} \\
(\mathrm{mmHg})\end{array}$ & $\begin{array}{c}88.5(31- \\
186)\end{array}$ & $85.5(40-128)$ & $\begin{array}{c}3 \\
(-20,27)\end{array}$ & 0.82 \\
\hline Intraoperative $p H$ & $7.27 \pm 0.09$ & $7.22 \pm 0.11$ & $\begin{array}{c}0.06 \\
(0.01,0.10)\end{array}$ & 0.018 \\
\hline $\begin{array}{l}\text { Intraoperative } \\
\mathrm{PaCO}_{2} \\
(\mathrm{mmHg})\end{array}$ & $\begin{array}{l}53.0(31.7- \\
93.6)\end{array}$ & $57.0(28.3-133)$ & $\begin{array}{c}-4.0 \\
(-9.0,4.4)\end{array}$ & 0.39 \\
\hline $\begin{array}{l}\text { Intraoperative } \\
\mathrm{PaO}_{2} \\
(\mathrm{mmHg})\end{array}$ & $109(25-274)$ & $139(27-330)$ & $\begin{array}{c}-30 \\
(-50,2)\end{array}$ & 0.07 \\
\hline EA/TEF (n) & 62 & 14 & & \\
\hline Preoperative $p H$ & $7.37 \pm 0.05$ & $7.39 \pm 0.04$ & $\begin{array}{c}-0.02 \\
(-0.06,0.02)\end{array}$ & 0.25 \\
\hline $\begin{array}{l}\text { Preoperative } \\
\mathrm{PaCO}_{2} \\
(\mathrm{mmHg})\end{array}$ & $40(32-55)$ & $41(33-76)$ & $\begin{array}{c}-1 \\
(-9,3)\end{array}$ & 0.35 \\
\hline $\begin{array}{l}\text { Preoperative } \mathrm{PaO}_{2} \\
(\mathrm{mmHg})\end{array}$ & $51(38-105)$ & $51(34-108)$ & $\begin{array}{c}0 \\
(-15,13)\end{array}$ & 0.6 \\
\hline Intraoperative $p H$ & $7.28 \pm 0.11$ & $7.20 \pm 0.11$ & $\begin{array}{c}0.08 \\
(0.01,0.15)\end{array}$ & 0.02 \\
\hline $\begin{array}{l}\text { Intraoperative } \\
\mathrm{PaCO}_{2} \\
(\mathrm{mmHg})\end{array}$ & $\begin{array}{c}50.6(22- \\
91.3)\end{array}$ & $58.8(30-91.7)$ & $\begin{array}{c}-8.3 \\
(-18.5,2.2)\end{array}$ & 0.1 \\
\hline $\begin{array}{l}\text { Intraoperative } \\
\mathrm{PaO}_{2} \\
(\mathrm{mmHg})\end{array}$ & $74(55-360)$ & $82(58-320)$ & $\begin{array}{c}-8 \\
(-38,0.9)\end{array}$ & 0.06 \\
\hline
\end{tabular}

Mean \pm SD or median (range); $\mathrm{CI}=$ confidence interval 
Table 3. Studies addressing intraoperative acidosis in neonates undergoing thoracoscopic CDH or EA/TEF repair.

\begin{tabular}{|c|c|c|c|c|c|}
\hline Reference & Study type & Pathology & Thoracoscopic & Open & Conclusions \\
\hline $\begin{array}{l}\text { Bliss et al } \\
2009[6]\end{array}$ & Retrospective & $\mathrm{CDH}$ & 31 & I & $\begin{array}{l}\text { Acidosis does not result } \\
\text { in clinically evident } \\
\text { compromise }\end{array}$ \\
\hline $\begin{array}{l}\text { McHoney et al } \\
2010 \text { [8] }\end{array}$ & Retrospective & $\mathrm{CDH}$ & 13 & 35 & $\begin{array}{l}\text { Thoracoscopic CDH } \\
\text { repair is feasible. } \\
\text { Arterial blood gases to } \\
\text { be closely monitored. }\end{array}$ \\
\hline $\begin{array}{l}\text { Fishman et al } \\
2011 \text { [9] }\end{array}$ & Ambispective & $\mathrm{CDH}$ & 12 & 9 & $\begin{array}{l}\text { Similar acidosis levels } \\
\text { between open and } \\
\text { thoracoscopic surgery }\end{array}$ \\
\hline $\begin{array}{l}\text { Mortellaro et al } \\
2011[\mathbf{1 0}]\end{array}$ & Retrospective & $\begin{array}{l}\text { CDH } \\
\text { EA/TEF }\end{array}$ & $\begin{array}{l}5 \\
12\end{array}$ & l & $\begin{array}{l}\mathrm{HFOV} \text { allows } \mathrm{CO}_{2} \\
\text { elimination to prevent } \\
\text { acidosis }\end{array}$ \\
\hline $\begin{array}{l}\text { Bishay et al } \\
2011 \text { [15] }\end{array}$ & Prospective & $\begin{array}{l}\text { CDH } \\
\text { EA/TEF }\end{array}$ & $\begin{array}{l}6 \\
2\end{array}$ & l & $\begin{array}{l}\text { Possible association of } \\
\text { acidosis and decreased } \\
\text { cerebral } \mathrm{O}_{2} \text { saturation }\end{array}$ \\
\hline $\begin{array}{l}\text { Ma et al } \\
2012[\mathbf{1 8}]\end{array}$ & Prospective & EA/TEF & 18 & 15 & $\begin{array}{l}\text { Thoracoscopic repair is } \\
\text { safe and tolerable in } \\
\text { selected patients }\end{array}$ \\
\hline $\begin{array}{l}\text { Bishay et al } \\
2013 \text { [12] }\end{array}$ & $\begin{array}{l}\text { Prospective } \\
\text { RCT }\end{array}$ & $\begin{array}{l}\text { CDH } \\
\text { EA/TEF }\end{array}$ & $\begin{array}{l}5 \\
5\end{array}$ & $\begin{array}{l}5 \\
5\end{array}$ & $\begin{array}{l}\text { No support for CDH } \\
\text { thoracoscopic repair. No } \\
\text { conclusive results for } \\
\text { EA/TEF repair }\end{array}$ \\
\hline $\begin{array}{l}\text { Okazaki et al } \\
2015 \text { [11] }\end{array}$ & Retrospective & $\mathrm{CDH}$ & 20 & 10 & $\begin{array}{l}\text { Thoracoscopy is safe for } \\
\text { the treatment of selected } \\
\text { cases }\end{array}$ \\
\hline $\begin{array}{l}\text { Tygat et al } 2015 \\
\text { [16] }\end{array}$ & Prospective & EA/TEF & 15 & I & $\begin{array}{l}\text { Cerebral oxygenation is } \\
\text { not hampered by } \mathrm{CO}_{2} \\
\text { insufflation at } 5 \mathrm{mmHg}\end{array}$ \\
\hline $\begin{array}{l}\text { Zani et al } \\
\text { current }\end{array}$ & Retrospective & $\begin{array}{l}\mathrm{CDH} \\
\mathrm{EA} / \mathrm{TEF}\end{array}$ & $\begin{array}{l}23 \\
14\end{array}$ & $\begin{array}{l}96 \\
62\end{array}$ & \\
\hline
\end{tabular}

$\mathrm{CDH}=$ congenital diaphragmatic hernia;

$\mathrm{EA} / \mathrm{TEF}=$ esophageal atresia/trachea-esophageal fistula;

$\mathrm{HFOV}=$ High frequency oscillatory ventilation.

Figure legends 
Figure 1: Arterial gas values for neonates undergoing open or thoracoscopic $\mathrm{CDH}$ repair.
A) Pre- vs. intra-operative $\mathrm{pH}$ values in the open surgery group;
B) Pre- vs. intra-operative $\mathrm{pH}$ values in the thoracoscopic surgery group;
C) Pre- vs. intra-operative $\mathrm{PaCO}_{2}$ values in the open surgery group;
D) Pre- vs. intra-operative $\mathrm{PaCO}_{2}$ values in the thoracoscopic surgery group;
E) Intraoperative $\mathrm{pH}$ values in neonates undergoing open vs. thoracoscopic surgery for $\mathrm{CDH}$;
F) Intraoperative $\mathrm{PaCO}_{2}$ values in neonates undergoing open vs. thoracoscopic surgery for $\mathrm{CDH}$.

Figure 2: Arterial gas values for neonates undergoing open or thoracoscopic EA/TEF repair.
A) Pre- vs. intra-operative $\mathrm{pH}$ values in the open surgery group;
B) Pre- vs. intra-operative $\mathrm{pH}$ values in the thoracoscopic surgery group;
C) Pre- vs. intra-operative $\mathrm{PaCO}_{2}$ values in the open surgery group;
D) Pre- vs. intra-operative $\mathrm{PaCO}_{2}$ values in the thoracoscopic surgery group;
E) Intraoperative $\mathrm{pH}$ values in neonates undergoing open vs. thoracoscopic surgery for EA/TEF;
F) Intraoperative $\mathrm{PaCO}_{2}$ values in neonates undergoing open vs. thoracoscopic surgery for EA/TEF. 
Figure 1

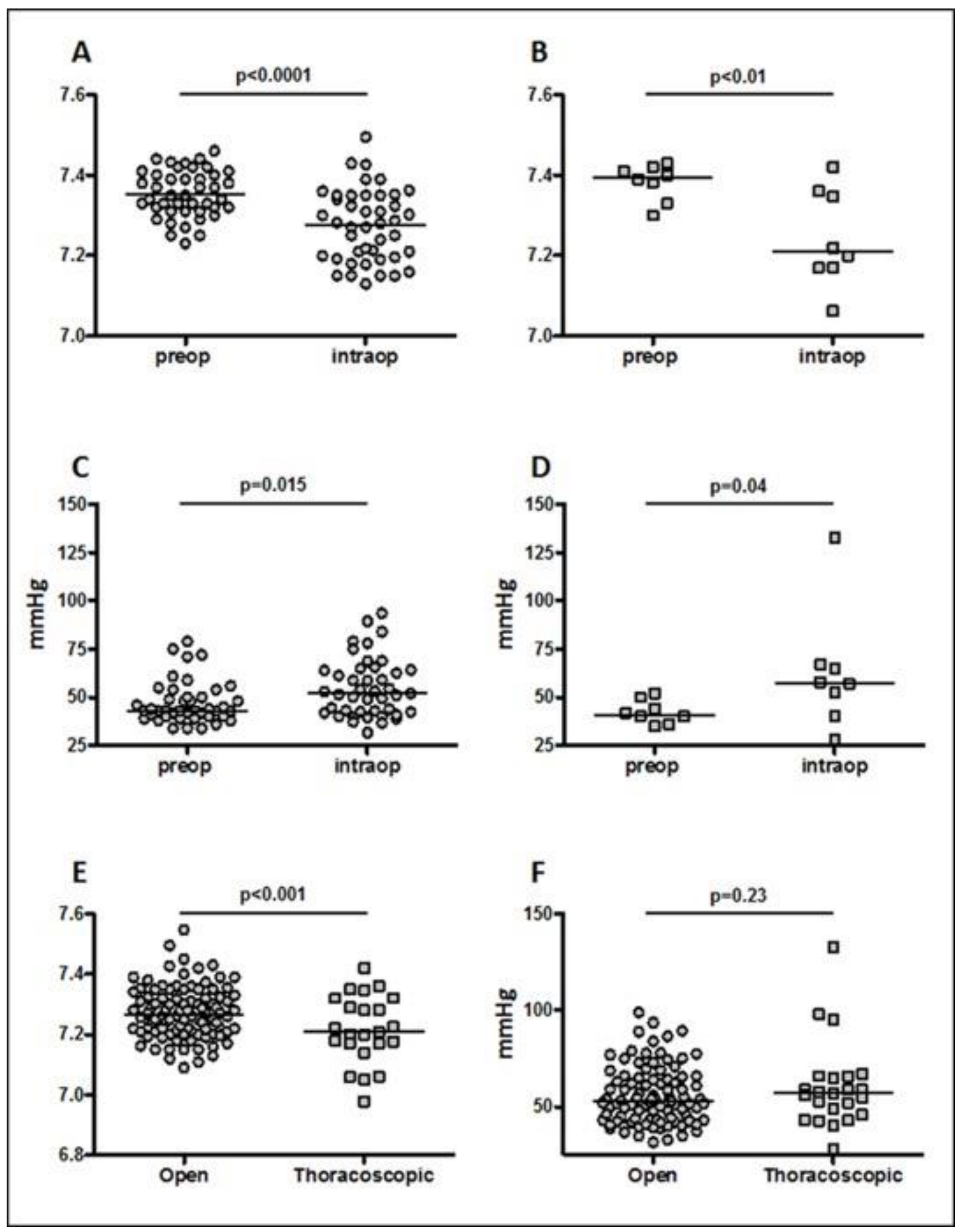


Figure 2

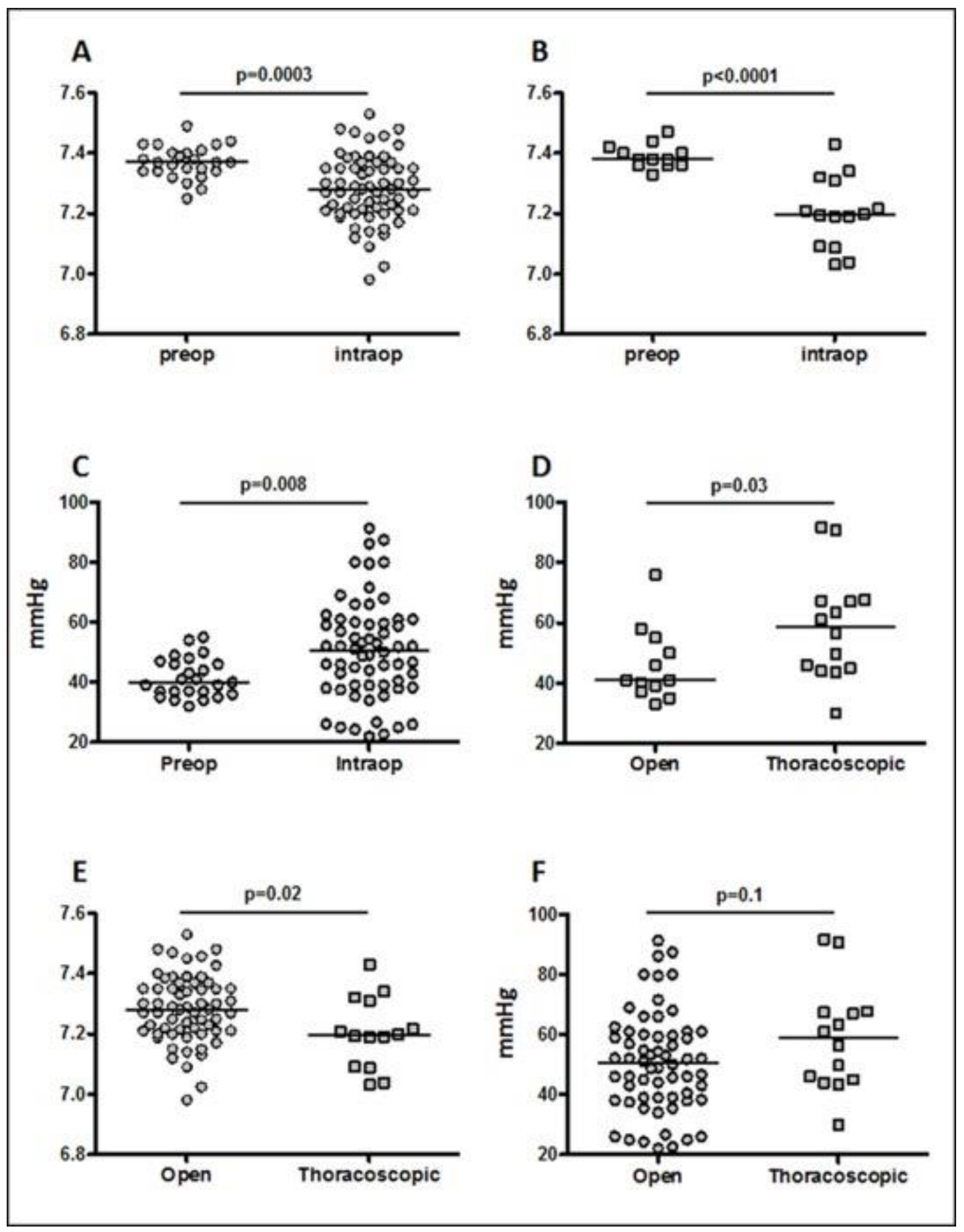

